\title{
Selection for Vulnerability to Angling in Largemouth Bass
}

\author{
DAVID P. PhILIPP* \\ Division of Ecology and Conservation Sciences, Illinois Natural History Survey, 1816 South Oak Street, \\ Champaign, Illinois 61820, USA; and Department of Natural Resources and Environmental Sciences, \\ University of Illinois at Urbana-Champaign, Urbana, Illinois 61801, USA

\section{Steven J. Cooke} \\ Division of Ecology and Conservation Sciences, Illinois Natural History Survey, 1816 South Oak Street, \\ Champaign, Illinois 61820, USA; and Fish Ecology and Conservation Physiology Laboratory, \\ Department of Biology and Institute of Environmental Science, Carleton University, \\ 1125 Colonel By Drive, Ottawa, Ontario, K1S 5B6, Canada \\ Julie E. Claussen \\ Division of Ecology and Conservation Sciences, Illinois Natural History Survey, \\ 1816 South Oak Street, Champaign, Illinois 61820, USA

\section{JEFFREY B. KOPPELMAN} \\ Missouri Department of Conservation, 1110 South College Avenue, Columbia, Missouri 65201, USA
}

\author{
CORY D. SUSKI
}

Department of Natural Resources and Environmental Sciences, University of Illinois at Urbana-Champaign, Urbana, Illinois 61801, USA

\section{Dale P. Burkett}

Great Lakes Fisheries Commission, 2100 Commonwealth Boulevard, Suite 100, Ann Arbor, Michigan 48105, USA

\begin{abstract}
Although a great deal of effort has been expended to try to understand the consequences of fishing-induced selection by commercial fisheries, relatively little effort has been put into trying to understand the selective effects of recreational angling. We conducted a long-term selection experiment to assess the heritability of vulnerability to angling in largemouth bass Micropterus salmoides. Three successive generations of artificially selected largemouth bass were produced from a single experimental study population. Within each generation, individual adult largemouth bass were identified as having either high or low vulnerability to angling through a series of controlled catch-and-release angling trials. Individuals of each vulnerability group (high and low) were then selected from that population for breeding to produce the next generation. The response to selection for vulnerability to angling increased with each generation; that is, the magnitude of the difference between the high- and low-vulnerability groups of fish increased with each successive generation. Realized heritability was calculated as $0.146\left(r^{2}=0.995\right)$, indicating that the vulnerability of largemouth bass to angling is indeed a heritable trait. Our results indicate that recreational angling has the potential to alter the gene pool of wild fish populations, which may indirectly affect population characteristics such as survival, growth rate, and reproductive output as well as directly affecting angling success rates.
\end{abstract}

In recent years, numerous studies have documented fishing-induced selection in commercially exploited marine fishes (e.g., Stokes and Law 2000; Heino and Godø 2002; Olsen et al. 2005). Such selection on life history traits can negatively affect not only the sustainability of the targeted fish populations but also

\footnotetext{
* Corresponding author: philipp@uiuc.edu
}

Received November 2, 2006; accepted August 5, 2008 Published online February 16, 2009 their long-term viability (Jennings et al. 1998; Conover 2000; Law 2000; Heino and Godø 2002). It is these selective forces that generate the need for fisheries managers to incorporate evolutionary theory into the management of exploited fish stocks (Law 2000; Stokes and Law 2000).

Although these examples have served to draw attention to the negative consequences of harvestinduced selection in commercial fisheries, relatively little effort has been devoted to understanding the 
effects of angling-induced selection in recreational fisheries. This lack of effort is somewhat surprising because large-scale recreational fisheries also have the potential to produce substantial selective effects (Cooke and Cowx 2006; Lewin et al. 2006). Moreover, because substantial reproductive failure (Philipp et al. 1997; Suski and Philipp 2004) or even mortality (Muoneke and Childress 1994; Arlinghaus et al. 2007) can still occur in recreational fisheries that are predominantly catch and release, there is the clear potential for selection to occur in populations of fish exposed to such presumably benign fisheries.

As has been documented for a variety of centrarchids and salmonids, vulnerability to angling (i.e., catchability) varies across taxa (Wege 1981). For example, several studies have assessed the differences in catchability between two closely related species, the largemouth bass Micropterus salmoides and its sister species, the Florida bass $M$. floridanus, when they were still considered subspecies (see Kassler et al. 2002 for a taxonomic history). Some authors concluded that the largemouth bass was generally more vulnerable than the Florida bass (Johnson 1975; Zolczynski and Davies 1976; Bottroff and Lembeck 1978; Johnson and Graham 1978; Rieger et al. 1978; Kleinsasser et al. 1990); others concluded that the two species were equally vulnerable to angling (Inman et al. 1978; Wright and Wigtil 1982). The difference may be due to the fact that several of the source populations used for one or both species were probably introgressed populations resulting from the mixture of the two (Philipp et al. 1983). Those authors that did find differences in vulnerability to angling between the two species offered a variety of hypotheses to explain those differences. Johnson (1975) speculated that the evolution of the Florida bass in shallow-water habitats made it less vulnerable, while Johnson and Graham (1978) believed the Florida bass was more excitable. Several authors suggested that the differences observed in catchability were based on differences in wariness and learning ability (e.g., Beukema 1970; Rieger et al. 1978; Askey et al. 2006). In fact, Garrett (2002) used the differential vulnerability of the two species to select individuals from a mixed population of bass, and he went on to show that the vulnerability differences remained after breeding to produce a new generation of each. Whatever the reason, it is not surprising that two different species have somewhat different vulnerabilities to angling.

From an evolutionary standpoint, intraspecific differences in vulnerability to angling may be more important than interspecific differences. Such differences have been documented for several species of salmonids (e.g., Dwyer 1990), and angling vulnerabil- ity has also been shown to vary among individuals and populations of largemouth bass, which as one of the most popular recreational fish in North America, experiences extremely high levels of angling pressure (Bennett 1954; Crumpton and Smith 1976). Intraspecific differences in vulnerability to angling may exist for a variety of reasons: (1) some individuals are more naive than others (Anderson and Heman 1969; Farabee 1970; Burkett et al. 1986), (2) some individuals are better able to recognize lures and learn to avoid them (Hackney and Linkous 1978; Clark 1983), (3) previous angling has reduced the number of catchable fish in a population (Redmond 1974; Mankin et al. 1984), (4) stress from handling affects the recapture rates for fish caught and released (O'Hara 1986), (5) individuals respond differently to external stimuli (Colgan 1986), (6) larger fish are more difficult to land (Mraz and Threinen 1957), and (7) ecological factors such as competition, type or abundance of prey, avoidance of predation, reproduction, diet, and habitat selection affect different individuals in different ways (Martin 1958; Howick and O'Brien 1983; Hart 1986).

We do know that increases in largemouth bass angling pressure lead to decreases in catch rates (Bennett 1954; Mraz and Threinen 1957; Martin 1958; Hackney and Linkous 1978; Mankin et al. 1984; Burkett et al. 1986). Such decreases, however, might not be due to selection, but rather to postharvest or postrelease (i.e., via delayed mortality) decreases in population abundance or behavioral alterations due to experiential learning. Yoneyama et al. (1994), however, compared the catchability of domestic and wild Mozambique tilapia Tilapia mossambica and concluded that susceptibility to capture had been altered by their different rearing histories through a form of artificial selection, suggesting that vulnerability to angling could be a heritable trait.

Studies on genetically based behavioral variation in fish have focused mainly on assessing the differences among line-bred strains of rainbow trout Oncorhynchus mykiss by comparing performance characteristics such as positioning, swimming, and responses to water current (Thomas and Donahoo 1977; Kelso et al. 1981). There are few clear demonstrations, however, that any one of these variable behaviors is actually heritable, and there are no documented studies that assess the heritability of vulnerability to angling (see Kuparinen and Merila 2007; Uusi-Heikkilä et al. 2008). Because vulnerability to angling is probably a product of feeding or aggression (Bryan and Larkin 1972), inherited proficiencies at discerning actual prey from artificial lures and limiting aggression toward artificial lures would increase the likelihood of survival. As a result, these traits would be selected positively within 
populations exposed to recreational angling. That is, our hypothesis is that if vulnerability to angling does in fact have a significant heritable component, removing the more vulnerable individuals in a given population would allow the less vulnerable individuals to perpetuate with greater success, thereby decreasing the average level of vulnerability to angling across the entire population. This type of selection experiment, which we propose has been going on in all bass lakes since the inception of angling, has the potential to alter, perhaps quite significantly, the behavior and even the life history of individual fish in those populations.

Understanding what controls vulnerability to angling is requisite for actually understanding how largemouth bass populations are affected by the various management strategies taken with them, including catch-andrelease angling. To begin to address these questions, Burkett et al. (1986) discussed the idea of creating high-vulnerability and low-vulnerability lines of largemouth bass by using differences in individual vulnerabilities to angling as the selection criterion. Our study reports the implementation of that idea, discussing the role that recreational angling can play in structuring fish populations and fisheries and examining the need to incorporate evolutionary theory into the management of recreational fisheries.

\section{Methods}

Study animals and selection experiments.-This study takes advantage of a large project evaluating the impact of catch-and-release angling on the fishery for largemouth bass that began in 1976 in Ridge Lake, Illinois (Burkett et al. 1986). Ridge Lake, an experimental reservoir (surface area, 7.10 ha) within Fox Ridge State Park, has been the site of much previous work on largemouth bass biology (e.g., Bennett 1954). From 1977 through 1980, all angling was controlled through a reservation process. All angled and landed largemouth bass were held in live wells on the boats from which they were captured until being creeled prior to release. At that time, the fish were measured, tagged (anchor tags; Floy Manufacturing), and fin-clipped so that the number of times individual fish were captured could be determined. In the early fall of 1980, Ridge Lake was drained, and all largemouth bass were collected. Growth and historical capture histories were then determined for all surviving bass (Burkett et al. 1986).

Based on their historical capture histories, individual largemouth bass were classified according to their relative vulnerability to angling. Individual fish that were not captured via angling at all during the 19771980 period were used as parents to establish a line to be selected for low vulnerability (LV) to angling.
Similarly, individual fish caught four or more times during the 1980 season were used to establish a line to be selected for high vulnerability (HV) to angling. These LV and HV adults ( $\mathrm{P}_{1}$ generation) were used as broodstock to produce the two lines of $\mathrm{F}_{1}$ offspring. Specifically, in early spring of 1981 , five HV malefemale pairs $\left(\mathrm{P}_{1}\right.$ fish from the surviving Ridge Lake population) were stocked into each of two brood ponds and five LV pairs in two other ponds (all 0.08 ha). Spawning was successful in all four brood ponds, and in late summer 1981 the brood ponds were drained. Age- $0 \mathrm{~F}_{1}$ offspring from all four ponds $(N=200 /$ pond $)$ were given a fin clip to identify them to line and then reared in a set of replicate common environments (three 0.08-ha rearing ponds) for three more years until they had matured and reached sizes where they were potentially vulnerable to angling.

During April 1984 the three rearing ponds were drained and recovered individuals from the two lines of largemouth bass were identified by fin clip. We stocked 60 similarly sized age- 3 fish of both sexes (impartially selected without regard for a particular sex ratio) into a 0.82-ha pond that did not contain largemouth bass. The fish were allowed to acclimate for about 2 months before angling began. Angling was spread over the summer months (mid-June to midSeptember), well after all spawning activity was completed. Two anglers fished simultaneously in blocks of $1 \mathrm{~h}$ using one of four artificial lures (white curlytail grub and jig, 7-cm silver floating stick bait, small chartreuse spinnerbait, $12-\mathrm{cm}$ black plastic worm) for $15 \mathrm{~min}$ each; the order in which the lures were used was rotated between angling trials. Every time a particular fish was captured, its fin clip was recorded, and it was marked as being captured by clipping the top third of a dorsal fin spine in posterior order, starting with the second (first full-sized) spine. Thus, the number of times every fish was captured could be identified from the fish's dorsal spine clip sequence.

After the summer of fishing pressure, $F_{1}$ test fish were collected from the pond by means of an AC boatmounted electrofishing unit. To select $F_{1}$ adults to be used for producing the next generation $\left(\mathrm{F}_{2}\right)$, captured individuals were identified to line by fin clip and their capture history determined by spine clip; HV fish caught three or more times were used as HV parents, and LV fish caught once or not at all were used as LV parents. During the spring of 1985, we stocked three HV pairs into one brood pond and three LV pairs into another pond. The resulting $\mathrm{F}_{2}$ offspring that were produced were treated as described above for the $F_{1}$ offspring; 200 age-0 fish from each $\mathrm{F}_{2}$ line were stocked into 0.08-ha grow-out ponds during September 
1985, where they were raised for 4 years to allow them to mature and reach catchable sizes.

During April 1989 these ponds were drained, and 75 similarly sized age-4 fish from each line were finclipped and used to establish the experimental population of $\mathrm{F}_{2}$ lines in a 1.27-ha pond. The fish were allowed to acclimate for about 2 months before angling began. Angling, spread over the same summer months, was conducted as with the $\mathrm{F}_{1}$ generation.

During September 1989, after the summer of fishing pressure, $\mathrm{F}_{2}$ test fish were collected by electrofishing as before to identify adults of each line to be used for producing the next generation $\left(\mathrm{F}_{3}\right)$ of selected fish. The $\mathrm{HV}$ fish that had been caught three or more times were used as HV parents, and LV fish that had been caught once or not at all were used as LV parents. During the spring of 1990, two replicate brood ponds were established for each line, with three pairs each. The resulting $\mathrm{F}_{3}$ offspring were treated like the $\mathrm{F}_{1}$ and $\mathrm{F}_{2}$ offspring, 200 age- 0 fish from each $\mathrm{F}_{3}$ line being stocked into 0.08-ha grow-out ponds during September 1990, where they were raised for 4 years to allow them to mature and reach catchable sizes.

During April 1994 these ponds were drained, and 30 similarly sized age-4 fish from each line were finclipped and used to establish the experimental population of $\mathrm{F}_{3}$ lines stocked in a 0.14 -ha pond. The fish were allowed to acclimate for about 2 months before angling began. Angling, again spread over the summer months, was conducted as with the $F_{1}$ and $F_{2}$ generations. However, fishing was terminated in early August because low dissolved oxygen levels killed an unknown number of test fish, but ample captures had been completed by that time.

Although the test fishing ponds varied in size, all had a maximum depth of less than $5 \mathrm{~m}$, had macrophyte cover throughout the pond, and had similar forage bases (i.e., bluegills Lepomis macrochirus and fathead minnow Pimephales promelas). All angling in the ponds was shoreline-based, but the entire surface area of each pond was accessible by angler casts. The anglers were project staff and students with a range of angling skills comparable to that of the anglers observed during the statewide creel surveys held over that period.

Calculation of vulnerability.-To compare the vulnerability to angling of the two lines of largemouth bass, both within years (i.e., within the same pond and exposed to the same angling pressure) and among years, we calculated vulnerability in two ways. The first method was based on directly comparing the numbers of captures (including recaptures). The first step was to calculate the total number of captures (TNC) for each line in each generation. To compare values across years, we then calculated the ratio $\mathrm{TNC}_{\mathrm{HV}}: \mathrm{TNC}_{\mathrm{LV}}$ for each generation.

Because the pond size, number of largemouth bass, and total hours fished varied among the three test generations, the second step was to calculate a total catch rate (TCR) for all of the fish in each line within each test pond. The equation for this was

$$
\mathrm{TCR}=\frac{\mathrm{TNC} / \text { number of hours fished }}{\text { number of bass } / \text { ha }} .
$$

This adjustment for differences in catch rate and stocking density allows for among-generation comparisons of this trait. The difference in TNC relative to the numbers of fish stocked for both lines during each generation was analyzed statistically using a chi-square contingency test.

The second method used to assess the relative vulnerability of the two lines was based on comparing rates of initial capture. Specifically, we calculated the time in cumulative hours of angling pressure required to capture (for the first time only) one-half of the individuals of each line in the test pond $\left(C_{50}\right)$. To compare vulnerability across years, we calculated for each generation the ratio of the $C_{50}$ for the $\mathrm{LV}$ line to that for the $\mathrm{HV}$ line. The difference in the time required to reach $C_{50}$ for the two lines during each generation was compared statistically by means of time-to-event analyses.

Quantification of realized heritability.-The realized heritability of a trait $\left(h^{2}\right)$ determines the relationship between the selection differential $(S)$ and the response to selection $(R)$ such that, when $h^{2}$ is between 0 and 1 , $h^{2}=R / S$ (Falconer 1981). The selection differential for a trait can be determined experimentally by selecting individuals with a high or low value for that particular trait to serve as the parents to produce a series of successive generations. The response to selection is quantified as the difference in phenotypic value between the progeny generation and the entire previous generation. Alternatively, the selection differential is the difference between the mean phenotypic value of the selected parents $\left(p_{s}\right)$ and the phenotypic value of the entire parental population $\left(p\right.$, where $\left.S=p_{s}-p\right)$. By selecting over several generations, the mean phenotypic value of each generation can be regressed against the cumulative selection differential to provide an estimate of the realized heritability. The cumulative selection differential $\left(S^{\prime}\right)$ is the sum of the selection differentials for the current generation and all previous generations combined. An even more robust estimate of heritability is obtained by performing a two-way selection experiment in which the trait is selected in both directions (Falconer 1981). In this way, the line 
TABLE 1.-Pond stocking and angling data for largemouth bass of the parental $\left(\mathrm{P}_{1}\right)$ and three subsequent generations $\left(\mathrm{F}_{1}\right.$, $\mathrm{F}_{2}$, and $\mathrm{F}_{3}$ ).

\begin{tabular}{crccrr}
\hline Generation & $\begin{array}{c}\text { Number } \\
\text { of fish }\end{array}$ & $\begin{array}{c}\text { Pond } \\
\text { size (ha) }\end{array}$ & $\begin{array}{c}\text { Density } \\
\text { (fish/ha) }\end{array}$ & $\begin{array}{r}\text { Hours } \\
\text { fished }\end{array}$ & $\begin{array}{r}\text { Total } \\
\text { captures }\end{array}$ \\
\hline $\mathrm{P}_{1}$ & 1,785 & 7.10 & 251 & 1,060 & 3,641 \\
$\mathrm{~F}_{1}$ & 120 & 0.82 & 146 & 123 & 230 \\
$\mathrm{~F}_{2}$ & 150 & 1.27 & 118 & 140 & 202 \\
$\mathrm{~F}_{3}$ & 60 & 0.14 & 429 & 14 & 68
\end{tabular}

a The number of fish in the $\mathrm{P}_{1}$ generation was the population of adult largemouth bass in Ridge Lake in 1980, which was based on the number of fish recovered when the lake was drained in the fall (Burkett et al 1986). In subsequent generations, one-half of the fish had high vulnerability to angling and the other half low vulnerability.

selected in the opposite direction serves as a reference for the other.

This latter approach was used in the current experiment; both HV and LV lines of largemouth bass were simultaneously selected in this experiment, and the response to selection (or divergence response for each generation) was estimated as the difference between the $\mathrm{HV}$ and $\mathrm{LV}$ lines. Additionally, to compensate for quantifying the differential response as the divergence between the $\mathrm{HV}$ and $\mathrm{LV}$ lines, the selection differential was summed for the two treatments for each generation and subsequently summed over all generations. To do this, we (1) calculated TCR to standardize catch rates across all test ponds and years, (2) calculated TCR for the entire test population by line and the mean TCR for individuals selected to serve as parents for the next generation, (3) calculated $S$ for each generation $\left(S=\mu_{s}-\mu\right.$, where $\mu_{s}$ is the mean TCR of the individuals selected as parents and $\mu$ is the mean TCR of the entire population), first separately for the HV and LV lines, then their sum for each generation's value, (4) calculated $S^{\prime}$ by adding the values of $S$ for each generation to the cumulative values of $S$ for all previous generations, and (5) calculated $R$ for each generation by subtracting the TCR values for $\mathrm{LV}$ fish from those for $\mathrm{HV}$ fish. Finally, we regressed $R$ against the $S^{\prime}$, and $h^{2}$ was determined as the slope of the line.

\section{Results}

Although population sizes, pond sizes, and levels of fishing pressure varied (Table 1), a clear pattern was seen in each of the three selected generations; the vulnerability to angling of the HV line was greater than that of the LV line, the differences observed between the two lines increasing across later generations (Figure 1). As early as the $F_{1}$ generation of vulnerabilityselected offspring, the cumulative number of captures for fish in the HV and LV lines diverged (Figure 1, top
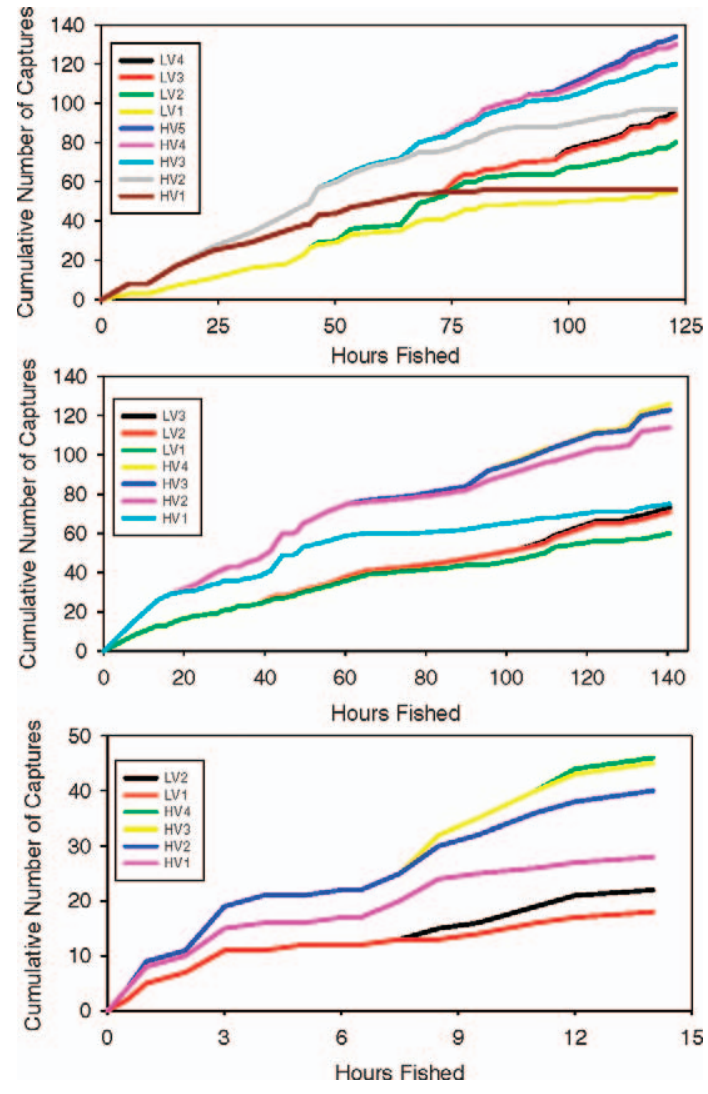

FIgURE 1.-Cumulative number of captures of highvulnerability (HV) and low-vulnerability (LV) largemouth bass relative to hours fished. The top panel shows results for the first generation of selected offspring $\left(\mathrm{F}_{1}\right)$, the middle panel results for the second generation $\left(\mathrm{F}_{2}\right)$, and the bottom panel results for the third generation $\left(\mathrm{F}_{3}\right)$. The number associated with each fish code is the number of captures for that line (e.g., HV3 represents data for the cumulative number of HV fish captured for the third time). Sample sizes per line are as follows: $F_{1}=60$ fish, $F_{2}=75$ fish, and $F_{3}=30$ fish.

panel). That is, the $60 \mathrm{HV}$ fish were captured a total of 135 times, whereas the $60 \mathrm{LV}$ fish were captured a total of only 95 times, a ratio of 1.42 (Table 2). The observed difference between lines in the TNC versus

TABle 2.- Total number of captures for the parental $\left(\mathrm{P}_{1}\right)$ stock and each of three generations $\left(F_{1}\right.$ to $\left.F_{3}\right)$ of largemouth bass selectively bred for (high) and against (low) vulnerability to angling ( $\mathrm{NA}=$ not applicable).

\begin{tabular}{ccccc}
\hline Generation & $\begin{array}{c}\text { Entire } \\
\text { population }\end{array}$ & $\begin{array}{c}\text { High } \\
\text { vulnerability }\end{array}$ & $\begin{array}{c}\text { Low } \\
\text { vulnerability }\end{array}$ & Ratio \\
\hline $\mathrm{P}_{1}$ & 3,641 & $\mathrm{NA}$ & $\mathrm{NA}$ & $\mathrm{NA}$ \\
$\mathrm{F}_{1}$ & 230 & 135 & 95 & 1.42 \\
$\mathrm{~F}_{2}$ & 202 & 128 & 74 & 1.73 \\
$\mathrm{~F}_{3}$ & 68 & 47 & 21 & 2.24 \\
\hline
\end{tabular}


TABLE 3.-Total catch rates (captures/h per bass/ha) for the parental stock $\left(\mathrm{P}_{1}\right)$ and each of three generations $\left(\mathrm{F}_{1}\right.$ to $\left.\mathrm{F}_{3}\right)$ of largemouth bass selectively bred for (high) and against (low) vulnerability to angling ( $\mathrm{NA}=$ not applicable).

\begin{tabular}{cccc}
\hline & \multicolumn{3}{c}{ Total catch rate } \\
\cline { 2 - 4 } Generation & Population & High vulnerability & Low vulnerability \\
\hline $\mathrm{P}_{1}$ & $1.36 \times 10^{-2}$ & $\mathrm{NA}$ & $\mathrm{NA}$ \\
$\mathrm{F}_{1}$ & $1.28 \times 10^{-2}$ & $1.50 \times 10^{-2}$ & $1.06 \times 10^{-2}$ \\
$\mathrm{~F}_{2}$ & $1.22 \times 10^{-2}$ & $1.54 \times 10^{-2}$ & $0.89 \times 10^{-2}$ \\
$\mathrm{~F}_{3}$ & $1.13 \times 10^{-2}$ & $1.57 \times 10^{-2}$ & $0.69 \times 10^{-2}$ \\
\hline
\end{tabular}

the number of individuals stocked, however, was not quite significantly different $\left(\chi_{1,350}^{2}=2.4, P=0.12\right)$. This divergence in TNC became more exaggerated and statistically significant as selection for the parental types continued through the $\mathrm{F}_{2}\left(\chi_{1,352}^{2}=6.3, P=0.01\right)$ and $\mathrm{F}_{3}\left(\chi_{1,128}^{2}=4.9, P=0.03\right)$ generations (Figure 1, middle and bottom panels). By the $\mathrm{F}_{3}$ generation, the $30 \mathrm{HV}$ fish were captured a total of 47 times, whereas the $30 \mathrm{LV}$ fish were captured a total of only 21 times, a ratio of 2.24 (Table 2). The differences in cumulative captures between the two lines of vulnerability were more apparent as hours of fishing pressure increased, although the time factor depended on the size of the test pond (which varied between years); the larger the pond, the more hours of fishing pressure were required to observe the divergence in capture rates between the two lines.

When the TNC is standardized for angling pressure (time fished in hours) and fish density (bass per hectare) across ponds and years (Table 3), an even more interesting pattern is observed (Figure 2); most of the selection response appeared to be in the LV line. Although an initial increase in vulnerability was noted in the $\mathrm{HV}$ line after the first generation of selection $\left(\mathrm{P}_{1}\right.$ $-\mathrm{F}_{1}$ ), selection rounds during the next two generations produced little increase. Conversely, selection response in the LV line continued over each generation.

Similar results occurred when vulnerability was calculated using initial catch rates (i.e., $C_{50}$ ) for each line in each generation (Table 4). That is, even in the $\mathrm{F}_{1}$ generation the $C_{50}$ for the LV line was $65 \mathrm{~h}$, whereas the $C_{50}$ for the $\mathrm{HV}$ line was $33 \mathrm{~h}$ (a ratio of 1.97), indicating that individuals in the $\mathrm{HV}$ line were caught for the first time with significantly less effort than individuals in the LV line $\left(\chi_{1}^{2}=6.2, P=0.01\right)$. In addition, the $C_{50}$ values for each of the two lines diverged increasingly through successive generations of selective breeding, the ratio of $C_{50}$ values between the two lines increasing to 2.18 by the $\mathrm{F}_{2}$ generation $\left(\chi_{1}^{2}=6.2, P=0.01\right)$ and 3.33 by the $\mathrm{F}_{3}$ generation $\left(\chi_{1}^{2}=\right.$ $2.6, P=0.1)$. Even though the ratio of the $C_{50}$ values was highest for the two lines in the $\mathrm{F}_{3}$ generation, the

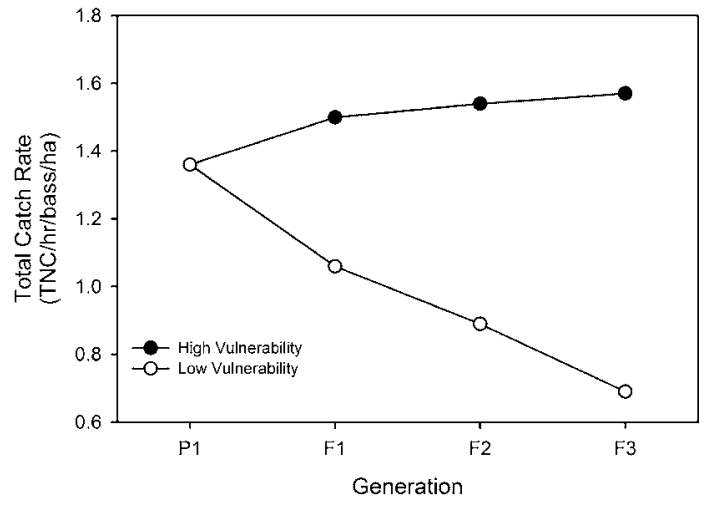

FIGURE 2.- Total catch rates of high-vulnerability and lowvulnerability largemouth bass, showing the divergence across three generations of selection from the parental $\left(\mathrm{P}_{1}\right)$ generation.

values were not statistically different, probably due to small sample sizes and short angling times.

In an effort to estimate the heritability of this trait, we calculated the TCR for not only the parental population and each subsequent selected line in each generation but also for those individuals selected as parents for each of the subsequent generations of selected lines (Table 5). The TCR of fish used as parents was consistently different from the population mean for that line. We then calculated $S$ for each generation and the cumulative selection differential across generations (Table 6). We calculated $R$ for each round of selection (Table 7) and regressed $R$ against $S^{\prime}$ (Figure 3); the resulting slope of $0.146\left(r^{2}=0.995, P=\right.$ $0.046)$, provides an estimate of the heritability, $h^{2}$, of vulnerability to angling for largemouth bass.

\section{Discussion}

Our study involving largemouth bass provides the first direct experimental evidence that vulnerability to angling is a heritable trait and, as a result, that recreational hook-and-line fisheries can cause evolutionary change in fish populations. We observed significant divergence between lines of largemouth

TABLE 4.- Half-capture life (the time of cumulative angling pressure required to capture, for the first time, $50 \%$ of the fish from a given group) for each of three generations $\left(F_{1}\right.$ to $\left.F_{3}\right)$ of largemouth bass selected for (high) and against (low) vulnerability to angling.

\begin{tabular}{cccc}
\hline Generation $(N)$ & Low vulnerability & High vulnerability & Ratio \\
\hline $\mathrm{F}_{1}(120)$ & 65 & 33 & 1.97 \\
$\mathrm{~F}_{2}(150)$ & 74 & 34 & 2.18 \\
$\mathrm{~F}_{3}(60)$ & 10 & 3 & 3.33 \\
\hline
\end{tabular}


TABLE 5.- Mean total catch rates (TCR; captures/h per bass/ha) for the entire line or population $(\mu)$ and for those individuals selected as parents $\left(\mu_{s}\right)$ for the next generation $\left(\mathrm{F}_{1}\right.$ to $\left.\mathrm{F}_{3}\right)$ of largemouth bass selected for (high) and against (low) vulnerability to angling.

\begin{tabular}{|c|c|c|c|c|c|c|c|}
\hline \multirow[b]{3}{*}{$\begin{array}{l}\text { Generation, } \\
\text { line }\end{array}$} & \multirow[b]{3}{*}{$\begin{array}{c}\text { Population mean } \\
\text { TCR }(\mu)\end{array}$} & \multicolumn{6}{|c|}{ Individuals selected as parents } \\
\hline & & \multicolumn{3}{|c|}{ High vulnerability } & \multicolumn{3}{|c|}{ Low vulnerability } \\
\hline & & $\begin{array}{c}\text { Number of } \\
\text { pairs }\end{array}$ & $\begin{array}{l}\text { Mean } \\
\text { captures }\end{array}$ & $\operatorname{TCR}\left(\mu_{s}\right)$ & $\begin{array}{l}\text { Number of } \\
\text { pairs }\end{array}$ & $\begin{array}{l}\text { Mean } \\
\text { captures }\end{array}$ & $\operatorname{TCR}\left(\mu_{s}\right)$ \\
\hline $\mathrm{P}_{1}$ & $1.36 \times 10^{-2}$ & 10 & 5.5 & $4.02 \times 10^{-2}$ & 10 & 0.0 & 0.00 \\
\hline $\mathrm{F}_{1}$, high & $1.50 \times 10^{-2}$ & 6 & 3.8 & $2.51 \times 10^{-2}$ & & & \\
\hline$F_{1}$, low & $1.06 \times 10^{-2}$ & & & & 6 & 0.9 & $0.45 \times 10^{-2}$ \\
\hline$F_{2}$, high & $1.54 \times 10^{-2}$ & 6 & 3.6 & $2.38 \times 10^{-2}$ & & & \\
\hline $\mathrm{F}_{2}$, low & $0.89 \times 10^{-2}$ & & & & 6 & 0.7 & $0.35 \times 10^{-2}$ \\
\hline$F_{3}$, high & $1.57 \times 10^{-4}$ & & & & & & \\
\hline $\mathrm{F}_{3}$, low & $0.69 \times 10^{-4}$ & & & & & & \\
\hline
\end{tabular}

bass selected for vulnerability to angling after three generations of directional selection. The magnitude of the difference between the two lines increased with each successive generation, indicating the strong selective component of the trait. Indeed, the realized heritability (i.e., the proportion of additive genetic variance in the total phenotypic variation) of angling vulnerability was calculated as 0.146 , which is comparable to the values obtained for other traits in other species, including total length in channel catfish Ictalurus punctatus (0.35; Bondari 1983), the growth rate in Altantic salmon Salmo salar (0.08; Refstie and Steine 1978), and the weight of different strains of channel catfish (0.24 and 0.34; Dunham and Smitherman 1983).

Humans and human activities have been tagged as the greatest evolutionary force currently acting on the globe (Sheridan 1995). As long ago as the 1950s scientists suggested that commercial fishing could result in genetic changes in fish populations (e.g., Miller 1957; Favro et al. 1979), this suggestion now being an accepted phenomenon (Smith et al. 1991; Heino and Godø 2002; Kuparinen and Merila 2007; Uusi-Heikkilä et al. 2008). In addition to genetic changes, the phenotypic correlates associated with selection can result in additional changes in population characteristics such as life history traits, behavior, and mortality rates (Law 2000; Heino and Godø 2002).
These authors reported that both the direct effects of fishing (i.e., elevated mortality) and the indirect effects (i.e., changes in system properties and function) can indeed result in fisheries-induced changes in the fish populations themselves, suggesting that fishing does have an evolutionary effect. In addition, Nuhfer and Alexander (1994) suggested that different levels of angler exploitation might have altered the genetic potential for growth and catchability of wild brook trout strains in Michigan. They proposed that angling tended to select against larger, faster growing individuals, and the removal of these fish resulted in the production of fewer fast-growing offspring.

In support of the hypothesis that fishing can act as a selective force, we point to a recent study by Conover and Munch (2002). The study revealed that after four generations, removal of the largest Atlantic silversides Menidia menidia (a common practice in both recreational and commercial fisheries) resulted in selection for individuals exhibiting slow growth. These authors estimated a relative heritability of 0.197 in both upward and downward directions relative to control fish. This conclusion (i.e., that harvest regulations favoring removal of larger individuals protects smaller individuals and can, in effect, reduce growth in a population) is relevant to both commercial and recreational fisheries. Although our study did not use a control line, making it difficult to measure change relative to

TABLE 6.- Selection differential, $S$, for each generation of largemouth bass $\left(\mathrm{P}_{1}\right.$ to $\left.\mathrm{F}_{3}\right)$ selected for (high) and against (low) vulnerability to angling, where $S$ is calculated as the difference between the total catch rate (captures/h per bass/ha) of the entire line $(\mu)$ and that of those individuals selected as parents for the next generation $\left(\mu_{\text {high }}\right.$ or $\left.\mu_{\text {low }}\right)$. Each line is calculated separately, then summed to determine that generation's $S$. The cumulative selection differential, $S^{\prime}$, is the sum of the $S$ values for the current generation and all previous generations of selection.

\begin{tabular}{ccccc}
\hline Generation of selection & $\mu_{\text {high }}-\mu$ & $\mu-\mu_{\text {low }}$ & $S$ & $S^{\prime}$ \\
\hline $\mathrm{P}_{1} \rightarrow \mathrm{F}_{1}$ & $2.66 \times 10^{-2}$ & $1.36 \times 10^{-2}$ & $4.02 \times 10^{-2}$ & $4.02 \times 10^{-2}$ \\
$\mathrm{~F}_{1} \rightarrow \mathrm{F}_{2}$ & $1.01 \times 10^{-2}$ & $0.61 \times 10^{-2}$ & $1.62 \times 10^{-2}$ & $5.64 \times 10^{-2}$ \\
$\mathrm{~F}_{2} \rightarrow \mathrm{F}_{3}$ & $0.84 \times 10^{-2}$ & $0.54 \times 10^{-2}$ & $1.38 \times 10^{-2}$ & $7.02 \times 10^{-2}$ \\
\hline
\end{tabular}


TABLE 7.-Divergence response to selection $(R)$ for each generation of largemouth bass $\left(\mathrm{P}_{1}\right.$ to $\left.\mathrm{F}_{3}\right)$ selected for (high) and against (low) vulnerability to angling, where $R$ is calculated as the difference between the total catch rates (TCR; captures/h per bass/ha) for the two lines in that generation (see Table 3).

\begin{tabular}{lccc}
\hline $\begin{array}{c}\text { Generation } \\
\text { of selection }\end{array}$ & $\mathrm{TCR}_{\text {high }}$ & $\mathrm{TCR}_{\text {low }}$ & $R$ \\
\hline $\mathrm{P}_{1} \rightarrow \mathrm{F}_{1}$ & $1.50 \times 10^{-2}$ & $1.06 \times 10^{-2}$ & $0.44 \times 10^{-2}$ \\
$\mathrm{~F}_{1} \rightarrow \mathrm{F}_{2}$ & $1.54 \times 10^{-2}$ & $0.89 \times 10^{-2}$ & $0.65 \times 10^{-2}$ \\
$\mathrm{~F}_{2} \rightarrow \mathrm{F}_{3}$ & $1.57 \times 10^{-2}$ & $0.69 \times 10^{-2}$ & $0.88 \times 10^{-2}$ \\
\hline
\end{tabular}

the preselected population, it appears that the bulk of the selection was in the direction of reducing vulnerability by selecting for less vulnerable fish rather than in the direction of increasing vulnerability by selecting for more vulnerable fish. Nonetheless, our findings clearly illustrate that angling vulnerability is indeed a heritable trait.

In light of this new evidence, one might ask why there are not more examples of fish populations in the wild showing such drastic responses to anglinginduced selection or why there have not been widespread decreases in largemouth bass catch rates if the vulnerability to angling has in fact decreased. We speculate that the failure to observe such changes in angler catch rates is due to the tremendous increases in angling technology (e.g., the advent of better terminal equipment, the development of fish locating devices, and the improvement in boat design and handling characteristics). Another possible explanation is that supplemental stocking activities have masked potential changes by altering the composition of a given population. It could also be simply that we just really have not looked for decreases per se because of the almost universal lack of background data on angling vulnerability in any standardized format that could be used to assess such evolutionary changes in fish behavior.

Our documentation of the heritable nature of the vulnerability to angling in largemouth bass will hopefully move researchers to look for some historical footprint of past selection. For example, populations of bass that have been subjected to many years of intense angling-induced selection should be inherently less vulnerable to angling than populations that have been spared such intense angling pressures. Experiments to assess this hypothesis in the wild would shed a great deal of light on just how substantial an effect this type of selection may be having on our current and future fisheries.

Understanding that angling-induced selection does in fact occur is in itself an important first step in elevating many aspects of our approach to manage-

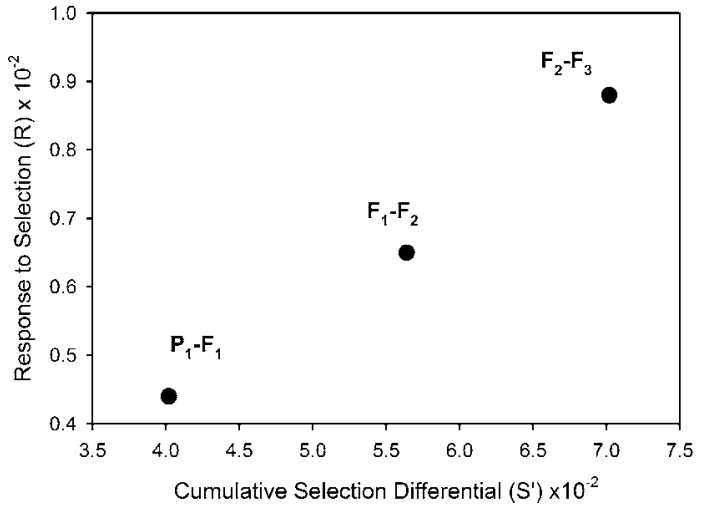

FIGURE 3.-Responses of largemouth bass of adjacent generations to selection for vulnerability to angling $(R)$ relative to the cumulative selection differential $\left(S^{\prime}\right)$. Four generations of fish were involved in these comparisons, ranging from the parental generation $\left(\mathrm{P}_{1}\right)$ to the third generation of offspring $\left(\mathrm{F}_{3}\right)$. Together, these two variables produce the estimate of realized heritability $\left(h^{2}\right)$ for angling vulnerability (here $0.146\left[r^{2}=0.995, P=0.0461\right]$ ).

ment. Determining to what extent that selection is capable of changing behaviors in populations of fish is an obvious next step (Uusi-Heikkilä et al. 2008). Until we begin to understand the mechanism(s) by which this selection alters the behavior(s) of the individual, however, we will not be able to manage our fisheries in an evolutionarily enlightened manner (Bull and Wichman 2001; Ashley et al. 2003; Stockwell et al. 2003). For example, vulnerability to angling could be primarily a product of feeding behavior (Bryan and Larkin 1972); a fish could strike a lure believing that it is food, either opportunistically or during directed foraging activities. In this scenario selection could favor either more discriminating individuals (i.e., those able to recognize lures and avoid them) or more riskaverse individuals (i.e., those unwilling to pursue prey in the presence of larger predators). These different selection mechanisms might result in evolutionary changes yielding quite different life history characteristics.

Vulnerability to angling could also be the product of an individual's general level of aggression (Bryan and Larkin 1972), that is, a largemouth bass could strike a lure simply as an act of aggression toward something entering its "space." In this scenario, selection would favor less aggressive individuals in general. As a byproduct, that type of selection could result in some undesirable changes in the population, such as decreased levels of parental care among male bass (i.e., males becoming less willing or able to defend their broods against potential predators). This scenario 
becomes much more plausible if much of the angling pressure occurs during the nesting period. It is evident that angling-induced selection can change characteristics of fish populations; we just do not know how or why. To address these questions, we are conducting additional experiments on our LV and HV lines of largemouth bass, as well as on wild populations of this species.

As a closing note, we would like to stress that the sole purpose for developing these directionally selected lines of largemouth bass was for the experimental assessment of the heritability of vulnerability to angling and the investigation into the mechanism(s) by which angling-induced selection acts to alter fish populations. Developing stocks that would be uniquely vulnerable to angling for enhancing private or public fisheries should not be a goal for this type of research for several reasons. First and foremost, because we do not understand the underlying basis of the behavioral differences between these lines of bass, we also have no knowledge whatsoever of the impact that introducing such line-selected fish might have on the fitness and behavior of wild populations. For example, angling may select against more aggressive or dominant individuals that provide better parental care to their offspring and, therefore, have higher fitness than less vulnerable conspecifics (Cooke et al. 2007). An alternative or complementary outcome could be that the individuals that had been selected for high vulnerability to angling have higher metabolic rates than those selected for low angling vulnerability. This higher metabolism might confer lower fitness to these fish because they would require greater food intake simply to grow at the same rate as other fish (Cooke et al. 2007). To accomplish that elevated foraging frequency, those individuals would undoubtedly have to take more risks, which would probably translate into lower survival.

Second, promoting the use of selected lines of fish for use in managing fisheries in the wild favors the use of some mythical quick fix rather than instituting the necessary steps to make needed management changes. Our largemouth bass fisheries involve wild populations. It would be a mistake to apply an inappropriate, agricultural approach to their management, rather than one based on evolutionary principles (see Ashley et al. 2003; Stockwell et al. 2003). Furthermore, fisheries management agencies that are attempting to manipulate catch rates in fish through some type of genetic manipulation (e.g., selective breeding, stock enhancement, and interspecific hybridization) should proceed with the utmost caution until the long-term implications of these actions are understood. As stewards of our important recreational fisheries, natural resource management agencies need to take a leadership role in using sound science to develop effective management programs that provide for the long-term conservation of natural fish populations. Understanding how angling impacts fish populations in evolutionary terms (not just demographic terms), and then using that knowledge to formulate new management approaches is an essential component of providing that leadership.

\section{Acknowledgments}

All of the experiments described in this study were conducted in accordance with the regulations and policies of the University of Illinois Office of Laboratory Animal Research. Financial assistance for this project was provided by the Illinois Natural History Survey and the Illinois Department of Natural Resources. Steven J. Cooke also acknowledges the assistance of the Natural Sciences and Engineering Research Council of Canada. We thank Robert Arlinghaus and several anonymous referees for providing detailed comments on the manuscript. We also want to thank the late William F. Childers for his outstanding foresight over 30 years ago; his life's work was the inspiration for this entire line of study.

\section{References}

Anderson, R. O., and M. L. Heman. 1969. Angling as a factor influencing the catchability of largemouth bass. Transactions of the American Fisheries Society 98:317-320.

Arlinghaus, R., S. J. Cooke, J. Lyman, D. Policansky, A. Schwab, C. D. Suski, S. G. Sutton, and E. B. Thorstad. 2007. Understanding the complexity of catch and release in recreational fishing: an integrative synthesis of global knowledge from historical, philosophical, social, and biological perspectives. Reviews in Fisheries Science 15:75-167.

Ashley, M. V., M. F. Willson, O. R. W. Pergams, D. J. O'Dowd, and S. M. Gende. 2003. Evolutionarily enlightened management. Biological Conservation 111:115-123.

Askey, P. J., S. A. Richards, J. R. Post, and E. A. Parkinson. 2006. Linking angling catch rates and fish learning under catch-and-release regulations. North American Journal of Fisheries Management 26:1020-1029.

Bennett, G. W. 1954. Largemouth bass in Ridge Lake, Coles County, Illinois. Illinois Natural History Survey Bulletin 26:217-276.

Beukema, J. J. 1970. Angling experiments with carp (Cyprinus carpio L.), II. Decreasing catchability through one-trial learning. Netherlands Journal of Zoology 20:81-92.

Bondari, K. 1983. Response to bidirectional selection for body weight in channel catfish. Aquaculture 33:73-81.

Bottroff, L. J., and M. G. Lembeck. 1978. Fishery trends in reservoirs of San Diego County, California, following the introduction of Florida largemouth bass, Micropterus salmoides salmoides. California Fish and Game 64:4-23.

Bryan, J. E., and P. A. Larkin. 1972. Food specialization by 
individual trout. Journal of the Fisheries Research Board of Canada 29:1615-1624.

Bull, J. J., and H. A. Wichman. 2001. Applied evolution. Annual Review of Ecology and Systematics 32:183-217.

Burkett, D. P., P. C. Mankin, G. W. Lewis, W. F. Childers, and D. P. Philipp. 1986. Hook-and-line vulnerability and multiple recapture of largemouth bass under a minimum total length limit of $457 \mathrm{~mm}$. North American Journal of Fisheries Management 6:109-112.

Clark, R. D., Jr. 1983. Potential effects of voluntary catch and release of fish on recreational fisheries. North American Journal of Fisheries Management 3:306-314.

Colgan, P. 1986. Motivational basis of fish behavior. Pages 23-46 in T. J. Pitcher, editor. The behavior of teleost fishes. Johns Hopkins University Press, Baltimore, Maryland.

Conover, D. O. 2000. Darwinian fishery science. Marine Ecology Progress Series 208:303-307.

Conover, D. O., and S. B. Munch. 2002. Sustaining fisheries yields over evolutionary time scales. Science 297:94-96.

Cooke, S. J., and I. G. Cowx. 2006. Contrasting recreational and commercial fishing: searching for common issues to promote unified conservation of fisheries resources and aquatic environments. Biological Conservation 128:93108.

Cooke, S. J., C. D. Suski, K. G. Ostrand, D. P. Philipp, and D. H. Wahl. 2007. Physiological and behavioral consequences of long-term artificial selection for vulnerability to recreational angling in a teleost fish. Physiological and Biochemical Zoology 80:480-490.

Crumpton, J. E., and S. L. Smith. 1976. Differences in growth and catchability of natural bass populations in Florida. Proceedings of the Annual Conference Southeastern Association of Fish and Wildlife Agencies 29(1975):330-336.

Dunham, R. A., and R. O. Smitherman. 1983. Response to selection and realized heritability for body weight in three strains of channel catfish, Ictalurus punctatus, grown in earthen ponds. Aquaculture 33:89-96.

Dwyer, W. P. 1990. Catchability of three strains of cutthroat trout. North American Journal of Fisheries Management 10:458-461.

Falconer, D. S. 1981. Introduction to quantitative genetics, 2nd edition. Longman, New York.

Farabee, G. B. 1970. Factors influencing the vulnerability of largemouth bass to angling and the comparative learning ability of selected fishes. Master's thesis. University of Missouri, Columbia.

Favro, L. D., P. K. Kuo, and J. F. MacDonald. 1979. Population-genetic study of the effects of selective fishing on the growth rate of trout. Journal of the Fisheries Research Board of Canada 36:552-561.

Garrett, G. P. 2002. Behavioral modification of angling vulnerability in largemouth bass through selective breeding. Pages 323-334 in David P. Philipp and Mark S. Ridgway, editors. Black bass ecology, conservation, and management. American Fisheries Society, Symposium 31, Bethesda, Maryland.

Hackney, P. A., and T. I. Linkous. 1978. Striking behavior of the largemouth bass and use of the binomial distribution for its analyses. Transactions of the American Fisheries Society 107:682-688.
Hart, P. J. B. 1986. Foraging in teleost fishes. Pages 211-235 in T. J. Pitcher, editor. The behavior of teleost fishes. Johns Hopkins University Press, Baltimore, Maryland.

Heino, M., and O. R. Godø. 2002. Fisheries-induced selection pressures in the context of sustainable fisheries. Bulletin of Marine Science 70:639-656.

Howick, G. L., and W. J. O’Brien. 1983. Piscivorous feeding behavior of largemouth bass: an experimental analysis. Transactions of the American Fisheries Society 112:508515.

Inman, C. R., R. C. Dewey, and P. P. Durocher. 1978. Growth comparisons and catchability of three largemouth bass strains. Proceedings of the Annual Conference Southeastern Association of Fish and Wildlife Agencies 30(1976):40-47.

Jennings, S., J. B. Reynolds, and S. Z. Mills. 1998. Life history correlates of responses to fisheries exploitation. Proceedings of the Royal Society of London B 265:333339.

Johnson, D. L. 1975. A comparison of Florida and northern largemouth bass in Missouri. Doctoral dissertation. University of Missouri, Columbia.

Johnson, D. L., and L. K. Graham. 1978. Growth, reproduction, and mortality factors affecting the management of largemouth and smallmouth bass. Pages 92 103 in G. D. Novinger and J. G. Dillard, editors. New approaches to the management of small impoundments. American Fisheries Society, Special Publication 5, Bethesda, Maryland.

Kassler, T., J. Koppelman, T. Near, C. B. Dillman, J. M. Levengood, D. Swofford, J. L. Van Orman, J. E. Claussen, and D. P. Philipp. 2002. Molecular and morphological analyses of the black basses: implications for taxonomy and conservation. Pages 291-322 in David P. Philipp and Mark S. Ridgway, editors. Black bass ecology, conservation, and management. American Fisheries Society, Symposium 31, Bethesda, Maryland.

Kelso, B. W., T. G. Northcote, and C. F. Wehrhahn. 1981. Genetic and environmental aspects of the response to water current by rainbow trout (Salmo gairdneri) originating from inlet and outlet streams of two lakes. Canadian Journal of Zoology 59:2177-2185.

Kleinsasser, L. J., J. H. Williamson, and B. G. Whiteside. 1990. Growth and catchability of northern, Florida, and $F_{1}$ hybrid largemouth bass in Texas ponds. North American Journal of Fisheries Management 10:462-468.

Kuparinen, A., and J. Merila. 2007. Detecting and managing fisheries-induced evolution. Trends in Ecology and Evolution 22:652-659.

Law, R. 2000. Fishing, selection, and phenotypic evolution. ICES Journal of Marine Science 57:659-668.

Lewin, W. C., R. Arlinghaus, and T. Mehner. 2006. Documented and potential biological impacts of recreational fishing: insights for management and conservation. Reviews in Fisheries Science 14:305-367.

Mankin, P. C., D. P. Burkett, P. R. Beaty, W. F. Childers, and D. P. Philipp. 1984. Effects of population density and fishing pressure on hook-and-line vulnerability of largemouth bass. Transactions of the Illinois State Academy of Science 77:229-240.

Martin, R. G. 1958. Influence of fishing pressure on bass fishing success. Proceedings of the Annual Conference 
Southeastern Association of Game and Fish Commissioners 11(1957):76-81.

Miller, R. B. 1957. Have the genetic patterns of fishes been altered by introductions or by selective fishing? Journal of the Fisheries Research Board of Canada 14:797-806.

Mraz, D., and C. W. Threinen. 1957. Angler's harvest, growth rate, and population estimate of the largemouth bass of Browns Lake, Wisconsin. Transactions of the American Fisheries Society 85:241-256.

Muoneke, M. I., and W. M. Childress. 1994. Hooking mortality: a review for recreational fisheries. Reviews in Fisheries Science 2:123-156.

Nuhfer, A. J., and G. R. Alexander. 1994. Growth, survival, and vulnerability to angling of three wild brook trout strains exposed to different levels of angler exploitation. North American Journal of Fisheries Management 14:423-434.

O'Hara, K. 1986. Fish behavior and the management of freshwater fisheries. Pages 496-521 in T. J. Pitcher, editor. The behavior of teleost fishes. Johns Hopkins University Press, Baltimore, Maryland.

Olsen, E. M., G. R. Lilly, M. Heino, M. J. Morgan, J. Brattey, and U. Dieckmann. 2005. Assessing changes in age and size at maturation in collapsing populations of Atlantic cod (Gadus morhua). Canadian Journal of Fisheries and Aquatic Sciences 62:811-823.

Philipp, D. P., W. F. Childers, and G. S. Whitt. 1983. A biochemical evaluation of the northern and Florida subspecies of largemouth bass. Transactions of the American Fisheries Society 112:1-20.

Philipp, D. P., C. A. Toline, M. F. Kubacki, D. B. F. Philipp, and F. J. S. Phelan. 1997. The impact of catch-andrelease angling on the reproductive success of smallmouth bass and largemouth bass. North American Journal of Fisheries Management 17:557-567.

Redmond, L. C. 1974. Prevention of overharvest of largemouth bass in Missouri impoundments. Pages 54 68 in J. L. Funk, editor. A symposium on overharvest and management of largemouth bass in small impoundments. American Fisheries Society, Special Publication 3, Bethesda, Maryland.

Refstie, T., and T. A. Steine. 1978. Selection experiments with salmon, III. Genetic and environmental sources of variation in length and weight of Atlantic salmon in the freshwater phase. Aquaculture 14:221-234.

Rieger, P. W., R. C. Summerfelt, and G. E. Gebhart. 1978. Catchability of northern and Florida largemouth bass in ponds. Progressive Fish-Culturist 40:94-97.

Sheridan, A. K. 1995. The genetic impacts of human activities on wild fish populations. Reviews in Fisheries Science 3:91-108.

Smith, P. J., R. I. C. C. Francis, and M. McVeagh. 1991. Loss of genetic diversity due to fishing pressure. Fisheries Research 10:309-316.

Stockwell, C. A., A. P. Hendry, and M. T. Kinnison. 2003. Contemporary evolution meets conservation biology. Trends in Ecology and Evolution 18:94-101.

Stokes, T. K., and R. Law. 2000. Fishing as an evolutionary force. Marine Ecology Progress Series 208:307-309.

Suski, C. D., and D. P. Philipp. 2004. Factors affecting the vulnerability to angling of nesting male largemouth bass and smallmouth bass. Transactions of the American Fisheries Society 133:1100-1106.

Thomas, A. E., and M. J. Donahoo. 1977. Differences in swimming performance among strains of rainbow trout (Salmo gairdneri). Journal of the Fisheries Research Board of Canada 34:304-306.

Uusi-Heikkilä, S., C. Wolter, T. Klefoth, and R. Arlinghaus. 2008. A behavioral perspective on fishing-induced evolution. Trends in Ecology and Evolution 23:419-421.

Wege, G. J. 1981. Fish and fishing in ponds with and without artificial structures. Master's thesis. University of Missouri, Columbia.

Wright, G. L., and G. W. Wigtil. 1982. Comparison of growth, survival, and catchability of Florida, northern, and hybrid largemouth bass in a new Oklahoma reservoir. Proceedings of the Annual Conference Southeastern Association of Fish and Wildlife Agencies 34(1980):31-38.

Yoneyama, D., T. Matsuoka, and G. Kawamura. 1994. Catchability of individual tilapia from wild and domestic groups. Bulletin of the Japanese Society of Scientific Fisheries 60:599-603.

Zolczynski, S. J., Jr., and W. D. Davies. 1976. Growth characteristics of the northern and Florida subspecies of largemouth bass and their hybrid, and a comparison of catchability between the species. Transactions of the American Fisheries Society 105:240-243. 